When given in conventional daily dosage, rifampicin is highly effective but very expensive, costing well over $£ 200$ a year for one patient. This makes the use of daily rifampicin regimens unrealistic in nearly all the developing countries and indeed in many technically advanced countries too. If an intermittent regimen containing a smaller total weekly dosage of rifampicin which is both therapeutically effective and of low toxicity could be found the applicability of this very valuable drug would be much increased. It would indeed be a great pity if the report of Dr. Poole and others were to be interpreted as discouraging further investigation along these lines.

In the final analysis the aim must be to evaluate rifampicin-containing regimens in terms of efficacy, safety, convenience, cost and applicability, in comparison with the alternative regimens available for the treatment of the same type of disease, in the same population.-We are, etc.,

DAVID J. GIRLING WALLACE FOX

M.R.C. Tuberculosis and Chest Diseases Unit,

London S.W.

1 Decroix, G., et al., Revue de Tuberculose et de Pneumologie, 1971, 35, 39

2 Verbist, L., et al., Proceedings of the Symposium on Rifampicin, Prague, 5-9 October, 1970, p.
104, Prague, Czechoslovak Medical Press, 1971.

\section{Undescended Testis}

SIR,-I feel it is time that the term orchidopexy was abandoned for the more rational operations to correct undescended testes.

Pexis $(\pi \eta \xi \iota \varsigma)$ means nailing or pegging, with the general implication of a rather rough job. Surgeons who take this operation seriously know the vital necessity to place the testis in the scrotum without the slightest hint of tension, no matter how extensive a procedure is necessary to achieve this end. If stitches to the thigh, or Torek or Ombrédanne procedures, or elastic bands, or scrotal pouches have to be done to keep the organ in the scrotum after operation, then it will surely die.

Chalasis $(\chi \alpha \lambda \alpha \sigma \iota s)$ means essentially loosening, untying, lowering gently into its natural position. The descriptive term orchiochalasy is therefore offered for what we are trying to do.-I am, etc.,

Beckenham,

W. VAN ESSEN

Kent

\section{Prophylaxis of Wound Infection}

Sir,-The results reported by $\mathrm{Mr}$. T. A. M. Stoker, and Professor H. Ellis (25 September, p. 769) from the Westminster Hospital prompted us to review the effect of powdered noxythiolin on our own wound infection rate. The results are part of a wound infection trial in which, after a wound swab was taken, nothing, saline, aqueous chlorhexidine, or noxythiolin are instilled into the wound at the end of the operation in a random manner. The wounds are inspected up to 10 days postoperatively by an observer who does not know the nature of the solution or powder used. The result in the first 176 wounds are:

\begin{tabular}{lc|c}
\hline & $\begin{array}{c}\text { No. of } \\
\text { Wounds }\end{array}$ & $\begin{array}{c}\text { No. of } \\
\text { Wound Infections }\end{array}$ \\
Nothing & 47 & 7 \\
Saline & 41 & 6 \\
Chlorhexidine & 44 & 3 \\
Noxythiolin & 44 & 11 \\
\hline
\end{tabular}

From these results it appears that neither chlorhexidine or noxythiolin is significantly better than nothing or saline in the prevention of wound infection. Secondly, the lower infection rate in the chlorhexidine group leads us to believe that there may be a significant reduction when more patients have been included. On the other hand, the results with noxythiolin suggest an increase in wound infection rate, and although there is no significant difference between the control group and the noxythiolin group, there is a significant difference at the $5 \%$ level $\left(\chi^{2}=5.4\right)$ between noxythiolin and aqueous chlorhexidine.

These results have led us to abandon the use of topical powdered noxythiolin in attempts to prevent wound infection, since there may even be an increase in wound infection associated with its use. The trial continues using aqueous chlorhexidine.-We are, etc.,

\section{K. C. Calman}

F. KENNEDY

Carolyn M. MEUdell

J. D. SLEIGH

Departments of Surgery and Bacteriology, Western Infirmary, Glasgow

\section{Epitaph for the M.C.H.C}

SIR,-We were interested to read the letter by Dr. Rose (16 October, p. 169), who cited some of our own unpublished work. ${ }^{1}$

We are not sure that our observations have been interpreted correctly. Perhaps we could clarify this matter by briefly describing our results. We have found that when the microhaematocrit method is used significant quantities of plasma are trapped between the centrifuged red cells. This produces a falsely high value for the packed cell volume (P.C.V.) and a falsely low value for the mean corpuscular haemoglobin concentration (M.C.H.C.). The error due to trapped plasma is smallest with blood samples from normal people. Here plasma trapping accounts for $3 \%$ of the packed red cell column. In iron deficiency, however, trapped plasma may account for $5-6 \%$ of the red cell column, and in blood with sickled red cells the plasma trapped may account for over $20 \%$ of the red cell column. The microhaematocrit method can therefore seriously overestimate the P.C.V. and seriously underestimate the M.C.H.C., especially in iron deficiency and in bloods with red cell sickling.

Anaemia per se is not responsible for the increased plasma trapping seen in iron deficiency, because if plasma is aspirated from sedimented blood samples so that the "haemoglobin" level becomes normal, increased plasma trapping is still evident.

We have concluded that the fall in M.C.H.C. in iron deficiency is to some extent artefactual. If allowance is made for trapped plasma in the microhaematocrit then the recalculated values of M.C.H.C. in iron deficiency are often within the accepted normal range. Under these circumstances it is not surprising that electronic counters, such as the Coulter $S$, produce normal estimates of the M.C.H.C. These machines do not centrifuge the sample, so there can be no error due to plasma trapping. The Coulter " $S$ ", for example, simply calculates the M.C.H.C. from direct measurements of the haemoglobin, the red cell count, and the mean cell volume.

In severe iron deficiency there appears to be a genuine fall in the M.C.H.C. even after correction for trapped plasma, and we have also found that these samples give a low M.C.H.C. on the Coulter " $S$ ". Our data emphasize the findings of Conrad and Crosby ${ }^{2}$ that the prime abnormality in hypochromia is the production of a small red cell with a normal haemoglobin concentration. Only in more severe deficiency does the haemoglobin concentration within the cell fall.

Like others, we have found a low mean corpuscular haemoglobin together with a low mean cell volume to be of great value in the diagnosis of iron deficiency and thalassaemia, and obviously these measurements now replace conventional M.C.H.C. in diagnosis.-We are etc.

J. M. ENGLAND D. M. WALFORD

D. A. W. WATERS

Department of Haematology,

Northwick Park Hospital and Clinical Research Centre, 1 England, J. M., Walford, D. M., and Waters, Conrad, M. E., and Crosby, W. H., Blood, 1962,

\section{Accidents at Work}

SIR,-In your leading article on the above subject (25 September, p. 722) reference is made, discussing the Annual Report of H.M. Chief Inspector of Factories, 1970,1 to "some notoriously hazardous occupations such as coal mining now employ fewer men. ." The accidents incurred by coal miners are not reported under the Factories Act but rather under the Mines and Quarries Act, and receive separate comment in the annual Report of H.M. Chief Inspector of Mines and Quarries. ${ }^{2}$-I am, etc.,

R. MCL. ARCHIBALD Society of Occupational Medicune

London N.W.1 1 Annual Report of H.M. Chief Inspector of 2 Ministry of Power. Report of H.M. Chief Inspector of Mines and
London, H.M.S.O., 1969.

\section{Iododeoxyuridine and Trachoma}

SrR,-In my review of Burnet's Genes, Dreams and Realities (18 September, p. 712) I stated, in reply to Burnet's claim that no human benefit whatever had yet been derived from the study of molecular biology, that a programme of fundamental research in this subject had yielded iododeoxyuridine, which was an effective chemotherapeutic agent in a number of severe virus infections of the eye, including trachoma. I am grateful 